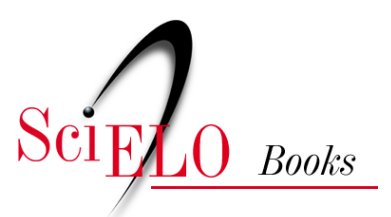

\title{
22 Tribo Coreopsideae Lindl.
}

\author{
Mara Angelina Galvão Magenta \\ Maria Alves \\ João Bernardo de A. Bringel Jr.
}

MAGENTA, M.A.G., ALVES, M., and BRINGEL JR., J.B.A. Tribo Coreopsideae Lindl. In: ROQUE, N. TELES, A.M., and NAKAJIMA, J.N., comp. A família Asteraceae no Brasil: classificação e diversidade [online]. Salvador: EDUFBA, 2017, pp. 165-170. ISBN: 978-85-232-1999-4.

https://doi.org/10.7476/9788523219994.0024.

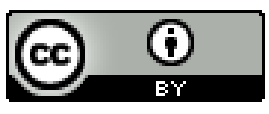

All the contents of this work, except where otherwise noted, is licensed under a Creative Commons Attribution 4.0 International license.

Todo o conteúdo deste trabalho, exceto quando houver ressalva, é publicado sob a licença Creative Commons Atribição $\underline{4.0}$. 


\title{
TRIBO COREOPSIDEAE LINDL.
}

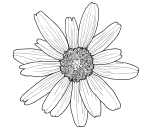 \\ Mara Angelina Galvão Magenta \\ Maria Alves \\ João Bernardo de A. Bringel Jr.
}

Coreopsideae foi proposta por Lindley (1829) para abranger 9 gêneros: Bidens L., Coreopsis L., Cosmos Cav. (Cosmea), Dahlia Cav., Heterosperma Cav., Parthenium L., Silphium L., Synedrella Gaertn. e Tetragonotheca L. Com base na circunscrição de Lessing (1830), que tratou o grupo como subtribo de Heliantheae (Coreopsidinae), Turner e Powell (1977) recircunscreveram a tribo Coreopsideae com a inclusão da subtribo Jaumeinae. A sugestão não foi bem aceita na comunidade científica, que passou a adotar o tratamento de Stuessy (1977), no qual Coreopsidinae foi considerada como subtribo de Heliantheae, incluindo 15 gêneros. No entanto, estudos moleculares (GOERTZEN et al., 2003; JANSEN et al., 1991; KIM et al., 1992; KIMBALL; CRAWFORD, 2004; PANERO; FUNK, 2002) corroboraram o status de tribo, e tal posicionamento foi adotado por Funk e colaboradores (2005) e Crawford e colaboradores (2009), que reconheceram a existência de 24 gêneros pertencentes à tribo.

Coreopsideae pode ser artificialmente delimitada pela presença de um conjunto de caracteres morfológicos, como as brácteas involucrais externas diferenciadas em forma e cor, a presença de estrias (ductos resiníferos) castanho-alaranjadas nas brácteas internas, pelas páleas do receptáculo lineares a lanceoladas com estrias contínuas às brácteas internas, pelas anteras e cipselas enegrecidas ou marrons e pelo pápus frequentemente de escamas ou aristas com tricomas antrorsos ou retrorsos (CRAWFORD et al., 2009; ROBINSON, 1981). 
As análises moleculares de Kimball e Crawford (2004) apontaram para o polifiletismo dos 2 maiores gêneros da tribo: Bidens e Coreopsis, que, futuramente, devem passar por reajustes em suas circunscrições taxonômicas. Por outro lado, o gênero Cosmos, que alguns autores consideram como sinônimo de Bidens, emergiu nas análises como monofilético. Segundo Crawford e colaboradores (2009), o maior desafio será encontrar características diagnósticas para os clados fortemente corroborados nos estudos filogenéticos moleculares já efetuados.

Em sua circunscrição atual (CRAWFORD et al., 2009), a tribo é composta por 24 gêneros e entre 593 e 599 espécies, e seus representantes são primariamente americanos, com alguns nativos da Austrália (Diodontium F. Muell., Glossocardia Cass. e Trioncinia (F. Muell.) Veldkamp) e 1 da Índia e Sri Lanka (Moonia Arn.). Embora não sejam reconhecidos na circunscrição de Crawford e colaboradores (2009), os gêneros Pinillosia Ossa ex DC. e Staurochlamys Baker foram inseridos em Coreopsideae por Panero (2007), com base em dados moleculares preliminares ainda não publicados. Esses gêneros apresentam morfologia muito distinta em relação ao restante de Coreopsideae e, no caso de Staurochlamys, a adição de mais dados moleculares a novas análises ainda poderá suportar seu reconhecimento como uma linhagem distinta ou dentro de Neurolaeneae (PANERO, 2007).

\section{Descrição}

Ervas, arbustos ou raramente pequenas árvores ou trepadeiras, glabros ou com vários tipos de indumento. Folhas simples, lâmina foliar com margem inteira a 3-pinatissecta. Capitulescência cimosa ou corimbosa, ou capítulo solitário, invólucro cilíndrico ou hemisférico. Capítulos heterógamos ou homógamos, radiados ou discoides; brácteas involucrais uni a multisseriadas, brácteas externas verdes, lineares a ovais, brácteas internas com 1 a muitas estrias castanho-alaranjadas, margens escariosas, às vezes com brácteas intermediárias orbiculares e foliáceas (Staurochlamys); receptáculo achatado a cônico, com páleas. Flores do raio neutras ou pis- 
tiladas, corola amarela, laranja, branca, rosa ou púrpura; flores do disco monoclinas ou funcionalmente estaminadas, corola tubular ou abrindose por uma cavidade que atravessa o lado ventral (Fitchia), com (4-)5 lobos curtamente triangulares, amarela, laranja ou amarelo-alaranjada; anteras (4-)5, marrons ou enegrecidas, raramente amareladas, curtamente caudadas; estilete inteiro ou curto-bifurcado, ramos cônicos com papilas curtas ou penicelados. Cipselas dorsalmente achatadas ou colunares, enegrecidas, marrons, raramente amarelo-amarronzadas ou vermelho-amarronzadas, lisas a estriadas, com ou sem alas; pápus de 2-8 aristas, lisas ou com cerdas antrorsas ou retrorsas, raramente com escamas, ou pápus ausente.

No Brasil, ocorrem 7 gêneros e cerca de 31 espécies, dos quais: Bidens, com 19 espécies (7 das quais são endêmicas), distribuído por todos os domínios fitogeográficos (Figuras 18A-C); Chrysanthellum Rich., representado por 1 única espécie encontrada em cerrado s.l.; Cosmos, com 3 espécies subespontâneas encontradas nos domínios da caatinga, cerrado, mata atlântica, pampa e pantanal (Figuras 18D-F); Coreopsis, com 1 espécie restrita ao Rio Grande do Sul; Isostigma Less., com 5 espécies encontradas nos domínios do cerrado e do pampa, 4 delas sendo endêmicas do país (Figura 18E); além de Staurochlamys, monoespecífico e endêmico do cerrado brasileiro e espécies ornamentais de Dahlia.

\section{Chave de identificação para os gêneros de Coreopsideae no Brasil}

1. Capítulos com 1 par de brácteas intermediárias nitidamente maiores que as demais, foliáceas e orbiculares. Flores do raio com pontuações glandulares Staurochlamys

1'. Capítulos sem par de brácteas involucrais foliáceas orbiculares. Flores do raio, quando presentes, sem pontuações glandulares.

2. Folhas em roseta basal 3

2'. Folhas opostas a alternas ao longo dos ramos 4 
3. Flores do raio com corola geralmente amarela; cipselas heteromorfas, cipselas do raio clavadas, sem pápus e cipselas do disco compressas, aladas, sem pápus ou raramente com pápus diminuto coroniforme ou de 2 aristas decíduas Chrysanthellum

3'. Flores do raio com corola geralmente roxa, amarelo-arroxeada ou atropurpúrea; cipselas isomorfas compressas, tetragonais, planas ou oblongas, sem alas ou com margem hialina estreita, pápus 2-aristado. Isostigma

4. Cipselas do disco geralmente aladas, de superfície rugosa a papilosa, com pápus de escamas caducas ou aristas com tricomas antrorsos Coreopsis 4'. Cipselas do disco sem alas, de superfície sulcada a finamente estriada, com pápus de aristas com tricomas retrorsos ou cerdas, ou cipselas sem pápus. 5

5. Flores do raio em mais de 3 séries; cipselas do disco de seção transversal compressa, sem pápus ou com pápus de 2 cerdas delicadas, caducas

Dahlia

5'. Flores do raio, quando existentes, em 1 ou 2 séries; cipselas do disco com seção transversal 4-angular, pápus de aristas com tricomas retrorsos ou raramente cipselas sem pápus 6

6. Cipselas sem rostro (Figura 15A); estames com filetes glabros Bidens 6'. Cipselas com rostro alongado (Figura 15B); estames com filetes hirsutos Cosmos

\section{Literatura recomendada}

BRINGEL JR., J. B. A., PASTORE, J. F. B.; CAVALCANTI, T. B. An unusual new species of Bidens (Asteraceae, Coreopsideae) with its phylogenetic position and taxonomic notes. Systematic Botany, Kent, v. 42, n. 2, p. 301-312, 2017.

CRAWFORD, D. J., et al. Coreopsideae. In: FUNK, V. A. et al. (Ed.). Systematics, Evolution and Biogeography of Compositae. Vienna: IAPT, 2009. p. 713-730.

CRAWFORD, D. J. et al. Coreopsis sect. Pseudoagarista (Asteraceae: Coreopsideae): Molecular phylogeny, chromosome numbers, and 
comments on taxonomy and distribution. Taxon, Utrecht, v. 63, n. 5, p. 1092-1102, 2014.

FUNK, V. A. et al. Everywhere but Antarctica: using a supertree to understand the diversity and distribution of the Compositae. Biologiske Skrifter, Copenhagen, n. 55, p. 343-374, 2005.

GOERTZEN, L. R. et al. ITS secondary structure derived from comparative analysis: implications for sequence alignment and phylogeny of Asteraceae. Molecular Phylogenetics and Evolution, Orlando, v. 29, n. 5, p. 216-234, 2003.

JANSEN, R. K. et al. Phylogeny and character evolution in the Asteraceae based on chloroplast DNA restriction site mapping. Systematic Botany, Kent, v. 16, p. 98-115, 1991.

KIM, K. J., R. K. et al. Phylogenetic implications of rbcL sequence variation in the Asteraceae. Annals of the Missouri Botanical Garden, Saint Louis, v. 79, n. 2, p. 428-445, 1992.

KIMBALL, R. T.; CRAWFORD, D. J. Phylogeny of Coreopsideae (Asteraceae) using ITS sequences suggests lability in reproductive characters. Molecular Phylogenetics and Evolution, Orlando, v. 33, n. 1, p. 127-139, 2004.

LESSING, C.F. Synanthereae. Linnaea, [S.1.], n. 5, p. 72-174, 1830.

LINDLEY, J. Suborder XVII. Heliantheae. In: LOUDON, J. C. (Ed.). An encyclopaedia of plants. London: Longman, Rees, Orme, Brown and Green, 1829. p. 1074.

MORT, M. E. et al. Phylogeny of Coreopsideae (Asteraceae) inferred from nuclear and plastid DNA sequences. Taxon, Utrecht, v. 57, n. 1, p. 109-112, 2008.

PANERO, J. L. Tribe Coreopsideae Lindl. In: KADERETT, J. W.; JEFFREY, C. (Ed.). The families and genera of vascular plant: v. VIII: Flowering plants eudicots: Asterales, Berlim: Springer, 2007. p. 406-417.

PANERO, J. L.; FUNK, V. A. Toward a phylogenetic subfamilial classification for the Compositae (Asteraceae). Proceedings of the Biological Society of Washington, Washington, v. 115, n. 4, p. 909-922, 2002. 
PETER, G. Systematic revision of the genus Isostigma Less. (Asteraceae, Coreopsideae). Candollea, Genebra, v. 64, n. 1, p. 5-30, 2009.

ROBINSON, H. A revision of the tribal and subtribal limits of the Heliantheae (Asteraceae). Washington: Smithsonian Institution Press, 1981.

(Smithsonian Contributions to Botany, v. 51).

SHERFF, E. E. Revision of the genus Isostigma Less. Botanical Gazette, Chicago, v. 81, n. 3, p. 241-257, 1926.

SHERFF, E. E. Revision of the genus Cosmos. Field Museum of Natural History, Botanical Series, Chicago, v. 8, n. 6, p. 441-447, 1932.

SHERFF, E. E. Revision of the genus Coreopsis. Field Museum of Natural History, Botanical Series, Chicago, v. 11, n. 6, p. 279-475, 1936.

SHERFF, E. E. The genus Bidens. Field Museum of Natural History, Botanical Series, Chicago, v. 16, p. 1-709, 1937.

SHERFF, E. E. Compositae - Heliantheae - Coreopsidinae. In: SHERFF, E. E.; ALEXANDER, E. J. (Eds.). North American Flora. New York: The New York Botanical Garden, 1955. v. 1, p. 1-149.

SMITH, E. B. A biosystematic survey of Coreopsis in eastern United States and Canada. Sida, Contributions to Botany, Dallas, v. 6, n. 3, p. 123-215, 1976.

SORENSEN, P. D. Revision of the genus Dahlia (Compositae - Heliantheae Coreopsidinae). Rhodora, Cambridge, n. 71, p. 367-416, 1969.

STUESSY, T. F. Heliantheae - systematic review. In: HEYWOOD, V. H.; HARBORNE J. B.; TURNER, E B. L. (Ed.). The Biology and chemistry of the Compositae. London: Academic Press, 1977. p. 621-671.

TADESSE, M.; CRAWFORD, D. J. The phytomelanin layer in traditional members of Bidens and Coreopsis and phylogeny of the Coreopsideae (Compositae). Nordic Journal of Botany, v. 32, p. 80-91, 2014.

TURNER, B. L. Taxonomic study of Chrysanthellum (Asteraceae, Coreopsideae). Phytologia, Huntsville, n. 64, n. 6, p. 410-444, 1988.

TURNER, B. L.; POWEL, M. A. Helenieae - systematic review. In: HEYWOOD, V. H.; HARBORNE, J. B.; TURNER, E. B. L. (Ed.). The Biology and chemistry of the Compositae. London: Academic Press, London: Academic Press, 1977. p. 699-737. 